\title{
Ressignificação das diferenças em múltiplos contextos
}

\author{
Maria Paula Frota, Maria das Graças Dias Pereira e Cilene Rodrigues
}

Este número da Revista escrita - seguindo o tema "Diversidade e inclusão: aspectos linguísticos, socioculturais e educacionais" - reúne onze artigos de excelência e relevância na contemporaneidade. Escritos ou coescritos por quase vinte pós-graduandos e professores, os estudos enriquecem o presente volume com a presença de inúmeros campos de formação e estudo, em uma dezena de instituições brasileiras que vão do Pampa gaúcho ao Rio Grande do Norte, somando-se a elas uma universidade portuguesa.

Já de início queremos registrar nosso prazer em ler os trabalhos, e nosso aprendizado, pois que, como verão os leitores, todos eles resultam de pesquisas que trazem consistência e novidades. De um modo geral instigantes, complexos e desafiadores, os textos despertam em nós o interesse de dialogar com os autores, em situação e momento propícios, em busca de maiores esclarecimentos quanto a resultados ou efeitos dos estudos realizados, suas contribuições de natureza bibliográfica, metodológica, tecnológica.

Nesta apresentação introdutória dos artigos, podemos adiantar que vários deles, movidos por múltiplos interesses (interpretação textual, letramento, argumentação escrita, gêneros textuais, dentre outros), encontram-se no campo do ensino-aprendizagem de língua portuguesa como L2, para Surdos. A multimodalidade comparece com frequência, assim como o tema das construções e desconstruções identitárias. Relações de poder, historicidade, questões ideológicas e sociais constituem, de igual modo, preocupação constante. Destaca-se o alerta contra preconceitos que discriminam identidades minoritárias - étnicas ou de gênero, por exemplo. Também são incluídas as pessoas com deficiência visual, por meio do tema da audiodescrição da cor em filmes.

Bem, passemos a uma apresentação individualizada dos trabalhos.

No artigo "Textos multimodais na aula de interpretação textual para surdos: uma proposta desafiadora e inclusiva", Leidiani da Silva Reis, doutoranda, e Iara Mikal Holland Olizaroski, mestranda, ambas do Programa de Pós-Graduação em Letras da Universidade Estadual do Oeste do Paraná (UNIOESTE), no âmbito de uma parceria com o Centro de Capacitação de Profissionais da Educação e de Atendimento às Pessoas com Surdez (CAS), da Secretaria Municipal de Educação de Cascavel-PR, fazem uma proposta de leitura e interpretação de charges. A proposta está inserida em um curso de Língua Portuguesa para Surdos, cujos alunos são professores surdos da Rede Municipal de Ensino no CAS, com ensino superior, e apresentam dificuldades na interpretação textual. O embasamento teórico, com foco na leitura e interpretação de textos, é de Angela Kleiman "Texto e leitor: aspectos cognitivos da leitura", a partir de três níveis de conhecimento: o linguístico, o textual e o de mundo. Em relação ao gênero charge, da esfera jornalística, a fundamentação é feita a partir de Michael Bakhtin "A estética da 
criação verbal", considerando elementos verbais e não verbais. Além da proposta pedagógica em Língua Portuguesa (L2), é interessante, no artigo, a menção à lei de obrigatoriedade do ensino de Libras (2002, 2005), a contextualização e discussão do ensino bilíngue Libras/Língua Portuguesa.

Vanessa Gomes Teixeira, doutoranda em Ciências da Linguagem na Faculdade de Letras da Universidade do Porto, contribui com o artigo "Trabalhando com gêneros e tipos textuais no ensino de português como segunda língua para surdos", no qual identifica uma significativa lacuna no contexto que o título apresenta. No sentido de mitigá-la, traz primeiramente discussões conceituais importantes e, a seguir, propõe uma variadíssima gama de atividades pedagógicas com textos autênticos. Essas atividades que a autora propõe - as quais visam trabalhar com histórias infantis e utilizam os gêneros conto de fadas, história em quadrinhos, propaganda e notícia -, embora com foco mais direcionado para o ensino da modalidade escrita do português, envolvem necessariamente atividades de leitura e interpretação, de reflexão e discussão com colegas e familiares. Antes de apresentar esse rico material, sempre preocupado com potenciais singularidades de práticas visuais da cultura surda, isto é, práticas sociais de interpretação de imagens, Vanessa Gomes Teixeira recorre a inúmeros autores, a começar por Bakhtin, com os quais elabora suas formulações e os efeitos pretendidos. Seu propósito é articular noções que possibilitem um melhor entendimento do que está implicado nesse trabalho de língua que, com gêneros e tipos textuais, também envolve diferentes tipos e níveis de letramento de Surdos, leitura e escrita, todos norteados pelo interesse em combater reducionismos e em promover uma participação integrada em estabelecimentos de ensino regular.

"Da Cinderela Ouvinte à Cinderela Surda: Análise multimodal e ensino" é a contribuição de Lorena Poliana Silva Lopes, mestranda em Linguística na Universidade de Brasília. Com base numa articulação entre categorias da gramática visual, da análise do discurso crítica e da semiótica social, é desenvolvida uma detalhada análise de duas versões de Cinderela, ou, como se verá, de $O$ sapatinho de vidro, um dos contos de fadas mais populares entre nós (incluídos os Surdos?). Atenta a diferentes aspectos históricos e sociais dos contextos em que as duas obras foram produzidas, distribuídas e consumidas, a autora põe em foco estratégias de produção de sentido e possíveis efeitos de leitura e interpretação das mesmas, especialmente em meio a alunos Surdos. Multimodalidade e intertextualidade são também noções-chave no exame dos modos semióticos verbal e não verbal, os quais podem comparecer e integrar-se em múltiplas formas e graus. Tem-se aqui uma contribuição importante não só para o ensino da linguagem verbal e visual, do Português e da Libras, como também para a difusão da cultura Surda em geral e de sua produção ou reescrita literária em particular.

No artigo "Argumentação em discursos escritos em língua portuguesa como L2 por professores surdos usuários de Libras", Gilton Sampaio de Souza, professor da área de Linguística, Mara Rúbia Pereira dos Santos, mestranda, Aluizio Lendl, mestrando, do Programa de Pós-Graduação em Letras da Universidade do Estado do Rio Grande do Norte (PPGL/UERN), fazem uma proposta de análise da argumentação em Língua 
Portuguesa como segunda língua - L2, de excertos de respostas por escrito a questionário/entrevista abertos, de dois participantes surdos bilíngues, professores de nível superior, colaboradores da pesquisa. As perguntas foram direcionadas à vida escolar dos participantes e ambos dominavam a escrita de Português como L2, além da leitura. A fundamentação teórica é da Nova Retórica, a partir do "Tratado da Argumentação: a Nova Retórica" (1958, 2005), de Perelman e Olbrechts-Tyteca, com foco na argumentação retórica do texto escrito, considerando a orientação lógica, a dialética e a estrutura da argumentação, com técnicas discursivas e outros elementos nos processos argumentativos. A tese que surge na análise dos excertos é a de que "a falta de intérprete na escola potencializou as dificuldades", mediante argumento pragmático de que há dificuldades na comunicação, com a falta de profissionais de interpretação. No argumento por superação, são relatados episódios da vida dos participantes em que não apenas eles mas também os pais nunca desistiram. No argumento por autoridade, surge a voz do pai, em discurso indireto, que justificaria a tese de que não haveria necessidade de o filho frequentar a escola. No argumento por ilustração, são relatadas dificuldades na escola, com o professor que deveria dominar Libras e a interação com alunos ouvintes. A análise dos excertos indica as dificuldades dos participantes surdos, ao longo de sua vida escolar.

Em "Preconceito e memória: por que na escola era tão difícil?", Adriana Maria Ribeiro Gil-Ferreira, doutoranda em Educação na PUC-Rio, faz uma relevante desconstrução, sobretudo a partir da filosofia hermenêutica de Gadamer, de pressupostos ainda vinculados a uma razão que se quer passar por universal e autônoma. Com essa opção crítica, é feito um alerta para o fato de que a escola - local privilegiado na formação de nossas memórias, de nossas formações identitárias - contribui intensamente para escritas menos ou mais positivas, ou negativas, das memórias infantis, em particular nos casos de crianças que experimentam identificações minoritárias. É na infância, tempo de maior susceptibilidade aos preconceitos e às formas como estes se manifestam, e é na escola, a depender do seu grau de conquista de autoridade, reconhecimento e conhecimento legitimados, que se escrevem essas memórias, as quais, não custa lembrar, levamos pela vida afora. Atenta à historicidade das conjunturas e dos sentidos, a autora não deixa de explicar que "preconceito" em princípio não é bom ou ruim, e propõe que a escola e os professores sempre se coloquem em questão e se abram para o diálogo; que busquem criticar as condições ainda hegemônicas que impõem o monólogo como única possibilidade; e que eventualmente transformem ou ressignifiquem seus preconceitos, o horizonte de sentidos que compartilham, de fato atentos e dando voz àqueles que aprendem.

O artigo "A variação linguística e a formação de professores/as de língua portuguesa", dos professores do Curso de Letras da Universidade Federal do Pampa Adriano de Souza e Taíse Simioni, discute propostas didáticas de alunos de graduação em Letras sobre como trabalhar a questão da variação linguística tomando como texto de base a letra da música Cuitelinho, do folclore do Mato Grosso. O objetivo desse estudo com alunos de Letras foi fomentar a discussão sobre as diferentes variantes do português brasileiro em seus 
diversos contextos de legitimação e não-legitimação. A partir de um olhar crítico sobre o posicionamento dos alunos de Letras em relação ao tema abordado, os autores apresentam uma sequência didática elaborada para discutir a questão do gênero discursivo dentro de cursos de letras. Como observam os autores, é imprescindível que cursos de Letras deem aos seus discentes uma formação crítica que lhes possibilite fazer análises de textos de maneira sistemática e coesa, buscando neles pistas linguísticas para determinadas conclusões. É imprescindível também que o discente desenvolva posição crítica sobre a variação dialetal existente no Brasil e suas implicações políticas e sociais.

"A audiodescrição e a cor no cinema: possibilidades para a acessibilidade do público com deficiência visual" parte de duas constatações: a primeira delas, a de que o cinema tem papel fundamental na contemporaneidade; a segunda, a de que a imagem é central no cinema, já que muito raros são os filmes que têm o som como único elemento narrativo. Uma vez contextualizado, o instigante tema em exame, como adianta o título, consiste na interpretação da cor por parte de espectadores com deficiência visual, principalmente daquelas pessoas com pouca ou nenhuma memória visual, e no complexo trabalho do audiodescritor quando se encontra diante dessa tarefa. As três autoras, formadas e/ou atuando na PUC-MG - Flávia Mayer, pós-doutoranda em Semiótica; Ana Cláudia Xavier, mestre em Interações Midiáticas e professora; e Sandra Sato, jornalista e mestre em Comunicação Social -, encaram o desafio, auxiliadas pelo Modelo Baseado em Direitos e convictas de que as pessoas com deficiência visual também podem vivenciar experiências de ver desde que expandidas as devidas ferramentas de acessibilidade, o conhecimento acerca da audiodescrição, sua profissionalização, leis e implementação de leis. As autoras insistem na urgência dessas iniciativas, bem como na urgência da superação de preconceitos. Para corroborar suas proposições, desenvolvem minuciosa pesquisa - que conta com consultoria e participação de pessoas com diferentes tipos de deficiência visual - sobre cada etapa do processo de audiodescrição de um filme publicitário que não apresenta nenhum diálogo ou narração (sendo, portanto, feito apenas de imagens) e traz cores diversas, as quais constituem o fio condutor da história.

Em "Para a relação sapatônica é um universo: A identidade de gênero em uma narrativa de história de vida", Thais Regina Santos Borges - especialista em Língua Inglesa pela PUC-RIO e mestranda em Estudos da Linguagem na mesma Universidade - apresenta análise de uma narrativa de história de vida contada por uma mulher em relacionamento homoafetivo estável. A narrativa, construída durante entrevista qualitativa com a analista, é instrutiva quando ao entendimento de como a identidade individual é construída dentro de um contexto social pós-moderno, em que a questão de escolha de gênero se coloca como pertinente. Como demonstra Thais, ao longo da narrativa, a narradora se constrói como dual: de um lado apresenta-se como orgulhosa de sua escolha sexual, e, ao mesmo tempo, deixa transparecer necessidade própria de conformar-se a um modelo social tradicional, com família bem composta e estável (com esposa, filhos e animal de estimação). Assim, a identidade da mulher narradora se faz na oposição ao modelo tradicional quanto à escolha de gênero e, de forma concomitante, na oposição ao modelo 
da comunidade LGBT quanto à estabilidade de relacionamentos afetivos. Como conclui a autora, a pesquisa por ela realizada mostra os caminhos por onde a identidade de gênero se constrói e se desconstrói de maneira fluida na prática discursiva, mediante aspectos internos e externos à pessoa que conta sua história.

Em "Performances de gênero e Teatro do Oprimido: desconstruindo velhas narrativas e propondo novas", Wograine Evelyn, aluna de Letras da PUC-Rio, discute a construção de gênero com alunos em idade escolar de uma comunidade carente, através da oficina de teatro do oprimido. O texto é organizado em três seções. Na primeira delas, a autora apresenta uma breve discussão sobre identidade no mundo pós-moderno. Na segunda, são discutidas teorias sobre gênero com ênfase na desconstrução da ideia tradicional de que os seres humanos nascem com gênero definido. Na última seção, são apresentados e discutidos os dados obtidos na oficina de teatro do oprimido sobre gênero. Embora os alunos carreguem consigo a visão tradicional da divisão de papéis entre homens e mulheres, é importante observar que participaram da oficina mostrando-se receptivos a reflexões sobre gênero, e, ainda que de forma tímida, apresentaram-se dispostos à desconstrução desses papéis. A beleza do trabalho elaborado está em mostrar que jogos educacionais envolvendo comunicação oral e gestual são objetos poderosos de transformação social.

Eva dos Reis Araújo Barbosa é mestranda do Programa de Pós-Graduação em Estudos Linguísticos pela Faculdade de Letras da UFMG, na área de concentração Linguística Aplicada, na linha de pesquisa Linguagem e Tecnologia. Em seu texto "Português como segunda língua e multimodalidade: análise de um vídeo tutorial para alunos surdos", o objetivo principal consiste em mostrar a análise de um vídeo tutorial criado para alunos ouvintes, alunos surdos que sabem Libras e alunos surdos que não sabem Libras. $\mathrm{O}$ vídeo Tutorial do bom navegador foi produzido em uma disciplina de Mestrado em Estudos Linguísticos. Foi criada uma questão de pesquisa online sobre os principais pontos turísticos da cidade de Belo Horizonte e sugestões foram dadas para que os alunos fizessem uma boa navegação. Os objetivos de criação do vídeo tutorial consistiram em criar oportunidades para os alunos e apoiar o trabalho do professor de português, mediante um recurso digital. Entre os procedimentos na elaboração do vídeo, foi feita a tradução Português/Libras do conteúdo do roteiro de gravação; a legendagem do vídeo, levando em consideração a interpretação em Libras, pelo uso do programa Movie Maker, dentre outros, antes da postagem na rede social Youtube. O vídeo é composto por diferentes modos de linguagem: imagem estática e em movimento, o sonoro pelo áudio, o verbal, o espacial e o gestual. Nos critérios de elaboração e de avaliação do vídeo, foram consideradas, como apoio teórico e metodológico, a Gramática do Design Visual (Kress e van Leeuwen, 2006), especialmente na função composicional (enquadramento, saliência e valor de informação), e a categoria público (Gomes, 2008). A avaliação feita é positiva em relação aos elementos focalizados.

No artigo "O universitário surdo: Questões de letramento e de autorrepresentações", Danielle Cristina Mendes Pereira e Valéria Campos Muniz, professoras, respectivamente, 
da UFRJ e do Instituto Nacional de Educação de Surdos (INES), tomam como objeto de estudo a construção da identidade do sinalizante surdo durante o processo de letramento em português brasileiro, como L2. As autoras realizaram pesquisa qualitativa, com dados obtidos por meio de questionários, entrevistas e informações sobre o cotidiano em sala de aula. Notou-se que os surdos iniciam o processo de letramento relativamente tarde, já no final da infância (idade mínima encontrada: 10 anos) e, embora a maioria dos participantes da pesquisa tenham apontado para a importância do letramento em suas vidas, ficou claro para as autoras que há resistência à aprendizagem de leitura e escrita em uma língua de base oral. Essa resistência está correlacionada ao contexto sóciohistórico de criação e de reconhecimento da Libras. Outro achado importante do trabalho é a relação entre o período de primeira exposição à Libras e o desempenho no processo de letramento em português. Os participantes que foram expostos à Libras ainda na primeira parte da infância (até os 4 anos) apresentaram melhor desempenho no processo de letramento em português, indicando que a exposição a uma língua de sinais ainda na primeira infância é essencial para o desenvolvimento de habilidades linguísticas e cognitivas de maneira geral (Quadros, 1997). Quanto ao papel do letramento em L2 na autorrepresentação do universitário surdo, as autoras indicam que, com o letramento, inicia-se a construção de uma autorrepresentação a partir da diferença, da pluralidade. Portanto, é preciso enfatizar não apenas os aspectos técnicos do letramento, mas também os contextos discursivos e ideológicos nos quais o processo e seus participantes estão inseridos.

Apresentadas as onze contribuições à nossa escrita, concluímos com enfáticas recomendações de sua leitura. 